\title{
REVIEW
}

\section{Current Clinical Trials on the Use of Direct Oral Anticoagulants in the Pediatric Population}

Erika von Vajna $\cdot$ Ruhaniyah Alam · Tsz-Yin So

To view enhanced content go to www.cardiologytherapy-open.com

Received: October 30, 2015 / Published online: January 6, 2016

(C) The Author(s) 2015. This article is published with open access at Springerlink.com

\section{ABSTRACT}

Common treatment options for deep vein thrombosis and venous thromboembolism in the pediatric population include unfractionated heparin, low molecular weight heparin, and warfarin. Other alternatives are bivalirudin, argatroban, and fondaparinux. Warfarin is the only approved oral option, but an oral agent without frequent monitoring would be optimal for pediatric patients. Thus, there is an increasing need for new anticoagulation options in this population. None of the current direct oral anticoagulants have FDA-approved indications and dosing in children. The two classes of DOACs and the drugs they are comprised of are factor $\mathrm{Xa}$ inhibitors (rivaroxaban, apixaban, edoxaban) and direct thrombin inhibitor (dabigatran). Off-label usage of these agents is largely based on adult doses. By

E. von Vajna $\cdot$ Tsz-Yin So $(\bowtie)$

Department of Pharmacy, Moses H. Cone Memorial

Hospital, Greensboro, NC, USA

e-mail: Jeremy.So@conehealth.com

R. Alam

University of North Carolina at Chapel Hill

Eshelman School of Pharmacy, Chapel Hill, NC, USA far, rivaroxaban and dabigatran have the most published data and ongoing trials in pediatric patients compared to edoxaban and apixaban. After evaluating the current literature available on these agents, it is, however, still too early to make any definitive recommendations on their usage in this special population.

Keywords: Anticoagulants;

Apixaban;

Dabigatran; Edoxaban; Pediatrics

\section{INTRODUCTION}

The need of anticoagulation in pediatric patients is increasing, and certain patient populations can be at an increased risk of developing deep vein thrombosis (DVT) and require venous thromboembolism (VTE) prophylaxis or treatment [1]. In neonates, anticoagulation is often needed when the thromboembolism is caused by a central venous access device or an umbilical venous catheter. The use of anticoagulation is also warranted in neonates with unilateral or bilateral renal vein thrombosis that extends into the inferior vena cava and with evidence of 
renal impairment, respectively. Many indications exist for thromboprophylaxis in the neonatal population, and these include but are not limited to patients post congenital cardiac surgery (e.g., modified Blalock-Taussig shunts) and patients with peripheral or umbilical arterial catheters who are at high risk of developing clots [2].

Similarly, children may also require anticoagulation after cardiac surgery (e.g., Glenn procedure or bilateral cavopulmonary shunt). Some children with moderate or giant coronary aneurysms following Kawasaki disease are also warranted to be on therapeutic doses of anticoagulants. Children with cancer are overall at an increased risk of developing VTE and can sometimes be seen on low molecular weight heparin for the treatment of deep vein thrombosis. A more detailed list of indications for antithrombotic therapy in neonates and children can be found in the CHEST guideline [2].

Unfractionated heparin (UFH), low molecular weight heparin (LMWH), or warfarin is often the anticoagulant of choice in the pediatric population [2]. If UFH and LMWH cannot be used due to heparin-induced thrombocytopenia and if warfarin is not an option due to the lack of oral access, other alternatives such as bivalirudin, argatroban, and fondaparinux can be used. Published literature exist in supporting the use of these three latter anticoagulants in pediatric patients [3-10]. Lepirudin has also been studied in children [11] but is not recommended by many clinicians because this anticoagulant appears to cause more bleeding in this population [12].

In recent years, direct oral anticoagulants (DOACs) have gained interest in their potential usage in pediatric patients. Factor Xa inhibitors and direct thrombin inhibitor comprise the DOACs. Rivaroxaban, apixaban, and edoxaban are the factor $\mathrm{Xa}$ inhibitors and dabigatran is the direct thrombin inhibitor. DOACs should be avoided in patients who are pregnant and patients with mechanical heart valves, rheumatic mitral stenosis, and stage $\mathrm{V}$ chronic kidney disease (except in patients on stable hemodialysis who desire to be on apixaban) [13-18]. Limited data exists on the use of these DOACs in pediatric patients, and none of them have Food and Drug Administration (FDA)-approved pediatric labeling. Off-label use of these DOACs in pediatrics is largely extrapolated from adult dosing guidelines. Fortunately, there are many clinical trials currently recruiting pediatric patients and are underway to assess their effects and efficacy in this special population. This article will attempt to summarize the current data and the ongoing trials being performed on their usage in pediatric patients.

\section{Compliance with Ethical Guidelines}

This article is based on previously conducted studies and does not involve any new studies of human or animal subjects performed by any of the authors.

\section{FACTOR Xa INHIBITORS}

In the coagulation cascade, factor $X$ is positioned at the convergence of the extrinsic and intrinsic pathways [13]. Its activation to factor Xa along with its binding with factor $\mathrm{Va}$ to form prothrombinase is essential for the conversion of prothrombin to thrombin [13]. Factor Xa inhibitors therefore directly decrease the amount of thrombin being produced in coagulation. Rivaroxaban, apixaban, and most recently edoxaban, are oral factor Xa inhibitors currently on the market in Europe and the United States. 


\section{Rivaroxaban}

Rivaroxaban, the first-approved DOAC, reversibly inhibits free and bound factor $\mathrm{Xa}$ as well as that in the prothrombinase complex ultimately preventing clot formation and growth [19]. Rivaroxaban has been shown to be non-inferior to low molecular weight heparin and warfarin in multiple studies in the adult population [20-24]. It is approved for use in adult patients to reduce the risk of thromboembolic complications associated with nonvalvular atrial fibrillation (NVAF), to treat and prevent recurrent DVT and pulmonary embolism (PE), and for preventing DVT in patients who underwent knee or hip replacement surgery [14]. Dosing in adults for the treatment and reduction in the risk of recurrent DVT and PE is $15 \mathrm{mg}$ by mouth twice daily with food for 21 days followed by $20 \mathrm{mg}$ by mouth once daily with food for the remainder of the treatment duration [14]. Along with the outcomes found in the adult non-inferiority studies, rivaroxaban carries additional advantages including once-daily dosing, high bioavailability, minimal drug interactions, and a limited need for laboratory monitoring [25]. These factors make rivaroxaban an appealing alternative to the currently recommended anticoagulants (i.e., warfarin, UFH, and $\mathrm{LMWH}$ ) in the pediatric population.

\section{Completed Studies}

Currently, there are only four completed studies assessing the pharmacokinetic and pharmacodynamic (PK/PD) effects of rivaroxaban in the pediatric population [19, $25,26]$. The first of these studies was an in vitro analysis of the differences in the pharmacodynamic effects of rivaroxaban in healthy children versus adults [25]. Plasma samples were obtained from healthy children ages 28 days to 16 years without a family history of coagulation disorders admitted to the hospital for minor day surgery. Plasma samples were grouped into age-specific pools, which were spiked with six different concentrations of rivaroxaban $(0,25,50,100,250$, and $500 \mathrm{ng} / \mathrm{ml})$ to match therapeutic levels of $100-300 \mathrm{ng} / \mathrm{ml}$ in plasma. Outcomes included the differences between measured activated partial thromboplastin time (aPTT), prothrombin time (PT), anti-factor Xa activity, and endogenous thrombin potential (ETP). The results of this trial failed to show a difference in age-related effect of rivaroxaban on any of the above-mentioned monitoring assays [25].

The second of these studies involved the development of a pharmacokinetic model for rivaroxaban 10 and $20 \mathrm{mg}$ in adults scaled to the pediatric population [19]. This study was conducted via physiologically-based pharmacokinetic (PBPK) simulation software, which considered lipophilicity, hepatic and renal clearance processes, gastrointestinal transit and absorption, as well as the effects food had on the medication. Using the adult model, a pediatric model was designed that included anthropometric and physiological information, age-dependent clearance processes of and protein binding in virtual children from term neonates to adolescents aged 18 years. Based on an average adult weight of $70 \mathrm{~kg}$, a pediatric weight-based dose was used. These included pediatric doses of $0.143 \mathrm{mg} / \mathrm{kg}(1 / 7 \mathrm{th} \mathrm{mg} / \mathrm{kg})$ and $0.286 \mathrm{mg} / \mathrm{kg}(2 /$ 7 th $\mathrm{mg} / \mathrm{kg}$ ), which would be equivalent to a $10-$ and 20-mg dose, respectively, in adult patients. The results of this study showed similar maximum concentration $\left(C_{\max }\right)$, area under the curve (AUC), and 24-h concentration $\left(C_{24 \mathrm{~h}}\right)$ values versus body weight. In children with body weight $>70 \mathrm{~kg}$, the simulated AUC 
and $C_{24 \mathrm{~h}}$ were much higher than the adult reference [i.e., $>90 \%$ confidence interval (CI)] so the weight-based doses for these children may be much higher than the 10 or $20 \mathrm{mg}$ used in adults. On the other hand, these values for either doses (i.e., 0.143 or $0.286 \mathrm{mg} / \mathrm{kg}$ ) in infants and children up to $40 \mathrm{~kg}$ of body weight were much lower than the adult reference population (i.e., $<90 \% \mathrm{CI}$ ) so higher doses in this weight group may be necessary [19].

Another study was presented as an abstract at the XXV Congress of the International Society on Thrombosis and Haemostasis and 61st Annual Scientific and Standardization Committee Meeting that recently took place in Toronto, Canada in June of 2015 [26]. The aim of this study was to determine a dose of rivaroxaban in pediatric patients aged 12-18 years that would result in an equivalent exposure seen with a 20-mg dose in adult patients for the treatment of VTE. By using a PBPK model, a weight-adjusted dose of rivaroxaban taken once daily was established for the cohort. The researchers initially performed a phase I single-dose PK/PD study comparing the predicted and observed plasma concentrations and AUC for the 10- $(n=4)$ and 20-mg $(n=5)$ equivalent doses. Both the observed concentrations and the AUC were similar to the prediction made by the PBPK model. Dose linearity was also observed between the 10- and 20-mg equivalent doses. This phase I study was followed by a 30-day multiple-dose PK/PD phase II study comparing the predicted and observed plasma concentrations and AUC for the 20-mg equivalent dose and evaluating the $\mathrm{PD}$ changes to the observed concentrations by measuring markers such as PT and aPTT. Eleven children with a mean age of 15.5 years were enrolled in this second study. Similar to the phase I study, the observed concentrations and the AUC were similar to the predicted model. Both the aPTT and PT showed an almost-linear relationship with the drug's plasma concentration. No major bleeding was observed in the study. From this data, the researchers concluded that pediatric patients weighing $30-50 \mathrm{~kg}$ will probably need $15 \mathrm{mg}$ daily and those weighing $>50 \mathrm{~kg}, 20 \mathrm{mg}$ daily of rivaroxaban, for the treatment of VTE. This dosing regimen is currently being studied in a phase III clinical trial with a similar cohort [26].

The last of these completed studies was recently completed and was a phase I trial assessing the pharmacokinetic and pharmacodynamic properties of oral rivaroxaban in the pediatric population [27]. The subjects included in this trial were those aged 6 months to $<18$ years who had completed treatment for venous thromboembolism but were considered to be at risk of recurrence. These subjects were given a single dose of weight-adjusted rivaroxaban equivalent to 10- or 20-mg dose in adults. The primary outcomes included AUC, $C_{\max }$, PT, aPTT, and anti-factor $\mathrm{Xa}$ from day 1 to day 2 post administration of rivaroxaban. The investigators also evaluated the safety and tolerability of this DOAC on day 1, 2, and 7 post dose. Even though this study was completed, the results have not yet been published on clinicaltrials.gov [27].

\section{Ongoing Studies}

Current ongoing studies evaluating the effects of rivaroxaban in the pediatric population include EINSTEIN Junior which is recruiting patients for two phase II and one phase III studies [28-30]. There are two phase II trials underway, which are both 30-day, open-label, active-controlled randomized studies of the safety/efficacy and pharmacokinetic/ 
pharmacodynamic properties of oral rivaroxaban in children with various manifestations of venous thrombosis [28, 29]. The difference between these two studies is the age of the participants. One of these studies includes participants ages 6 months to $<6$ years and the other includes participants ages 6 to 17 years. Participants enrolled in either trial are those entering their last month of anticoagulant therapy after having been treated with LMWH, fondaparinux and/or vitamin $\mathrm{K}$ antagonist (VKA) for at least 2 months or for at least 6 weeks in patients who have had catheter-related thrombosis [28, 29].

Similarly, the phase III trial is an open-label, active-controlled, randomized study assessing the safety and efficacy of rivaroxaban in comparison to the standard of care including subcutaneous LMWH, fondaparinux and/or oral VKA in patients with confirmed acute venous thromboembolism [30]. Children included in this trial are those ages 6 months to $<18$ years who were initially treated with unfractionated heparin, LMWH, or fondaparinux and required anticoagulant therapy for at least 90 days. In this trial, rivaroxaban will be provided according to an age- and body weight-adjusted dosing schedule to achieve concentrations similar to those observed in adult patients on $20 \mathrm{mg}$ of rivaroxaban. It will be provided as a 20-mg equivalent tablet given once daily for children $12-18$ years of age and subsequently as a 20-mg equivalent oral suspension given twice daily for children ages 6 months to $<12$ years [30] (Fig. 1). The results of all of these ongoing studies are pending and yet to be published.

Another ongoing study is a multicenter, international, phase I study evaluating a rivaroxaban dry powder suspension in pediatric patients ages 6 months to 12 years with previous history of thrombosis [31].
Subjects will be included if they have finished treatment with an anticoagulant at least 10 days and have normal PT and aPTT within 10 days before enrolling into the study. The primary outcomes will be the measurement of AUC and $C_{\max } 20$ to $24 \mathrm{~h}$ after the administration of the studied suspension. This study will also evaluate the PT, aPTT, and anti-Xa activity of rivaroxaban between the aforementioned timeframe and will be compared to baseline values that will be obtained within $5 \mathrm{~h}$ prior to drug administration [31]. Similar studies evaluating the bioavailability of a rivaroxaban oral suspension have recently been completed in adults. [32, 33]. It will be interesting to compare theses adult data with the pediatric data when they become available. Establishing a bio-equivalent oral suspension of rivaroxaban will be a vital step in potentially administering this DOAC to younger pediatric patients.

The last ongoing study is both a phase I and phase II study that will assess the safety, efficacy, and pharmacokinetic/ pharmacodynamic properties of oral rivaroxaban in patients less than 6 months of age with catheter-related thrombosis who have been treated for at least 2 weeks of standard therapy with heparin and/or warfarin [34]. This study will take place in 11 countries such as Australia, France, Israel, and the United States. The subjects will be given a 7-day treatment of an age- and body weight-adjusted oral rivaroxaban given twice daily as a $1-\mathrm{mg} / \mathrm{ml}$ oral suspension to achieve similar exposures as those observed with 20-mg daily dosing in adults. The primary outcome will be the plasma concentration of rivaroxaban in this cohort from day 1 to day 8. As secondary endpoints, the investigators will assess the incidence of major bleeding, clinically relevant non-major bleeding, and symptomatic recurrent thromboembolism on days 1 to 7 . 


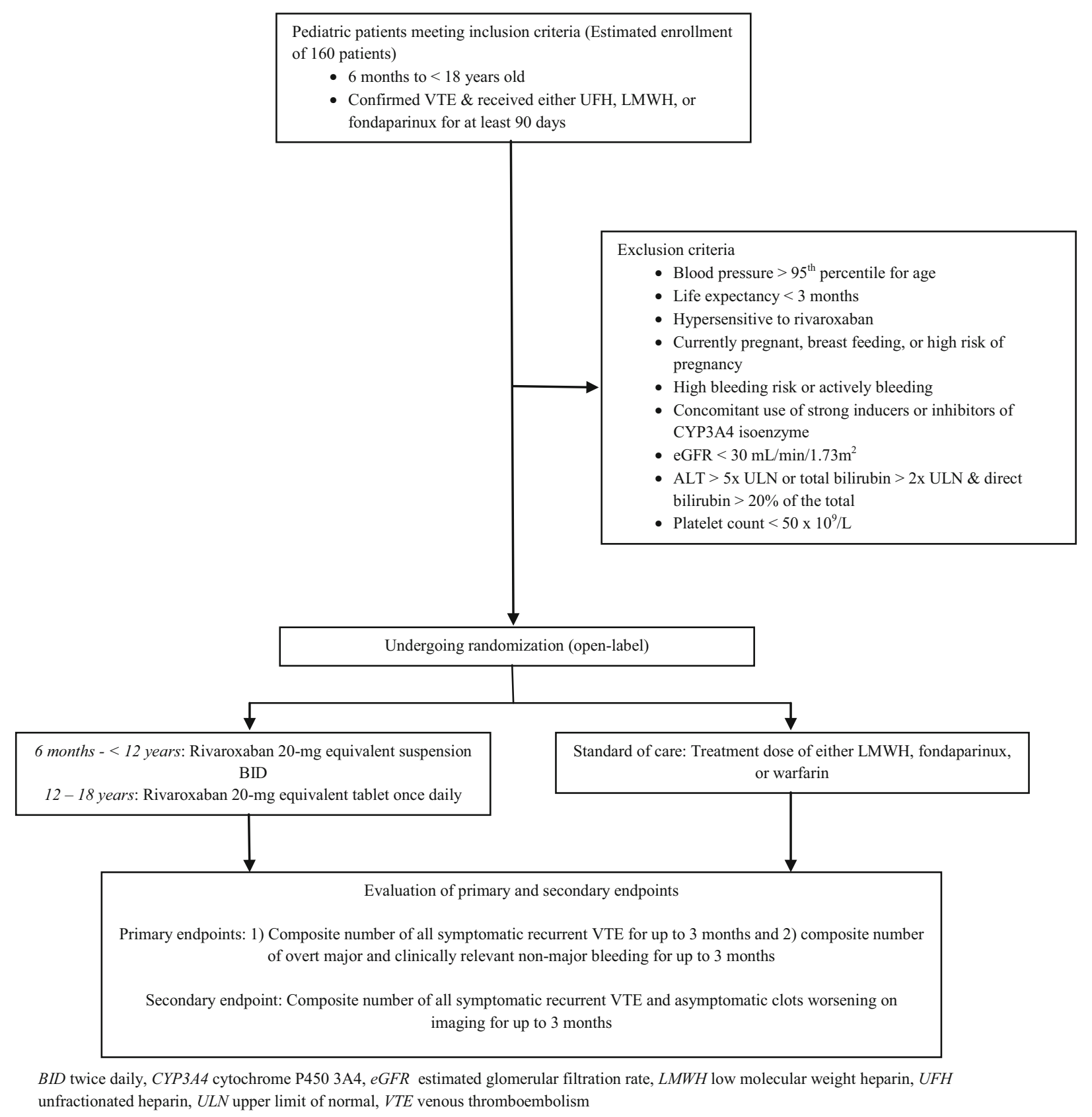

Fig. 1 Design of oral rivaroxaban in children with venous thrombosis (EINSTEIN Junior Phase III Study) [30]

The incidence of asymptomatic worsening of thrombotic burden will also be evaluated on day 8 post administration of rivaroxaban [34]. The results of all these ongoing studies will be vital to the approval of rivaroxaban use in the pediatric population.

\section{Apixaban}

Similar to rivaroxaban, apixaban is a reversible factor $\mathrm{Xa}$ inhibitor that inhibits free, bound, and complexed factor $\mathrm{Xa}$ [15]. It has gained approval for the prevention of thromboembolic 
complications in adult patients who have undergone hip or knee replacement $[35,36]$. It was also found to be superior to warfarin for the risk reduction of stroke and systemic embolism in patients with atrial fibrillation [37]. Most recently, it has been approved for the treatment of DVT and PE and the reduction in the risk of recurrent DVT and PE following initial therapy $[38,39]$. The recommended dosing for the treatment of DVT and PE in adults is $10 \mathrm{mg}$ by mouth twice daily for 7 days, followed by $5 \mathrm{mg}$ by mouth twice daily [15]. Dosing for the prevention of DVT following hip or knee replacement surgery or for the reduction in the risk of recurrent DVT and PE following initial therapy is $2.5 \mathrm{mg}$ by mouth twice daily [15].

\section{Completed Study}

Currently, there are not any published trials assessing the efficacy of apixaban in the pediatric population. In 2012, a multi-dose study of apixaban in the pediatric population was terminated for unknown reasons [40]. This study was designed to assess the pharmacokinetic and pharmacodynamic properties of apixaban in patients aged 12 to $<18$ years with a functioning central venous catheter. The study drug was given at a low dose of $0.66 \mathrm{mg} / \mathrm{m}^{2}$ twice daily for 10 days or a high dose of $1.32 \mathrm{mg} / \mathrm{m}^{2}$ as an oral solution twice daily for 10 days [40]. No other information was published or available on this trial and the researchers did not mention a reason for the early discontinuation of this study.

\section{Ongoing Studies}

To date, there are three ongoing studies assessing the potential use of apixaban in pediatric patients [41-44]. The first of these studies is a phase I single-dose, parallel study evaluating the $\mathrm{PK}$ and $\mathrm{PD}$ parameters of apixaban as a preventive regimen in subjects ages 37 weeks to 18 years at risk for a venous or arterial thrombotic disorder [41]. Five different groups are assigned in this study. Group 1 includes neonates who are given an unspecified dose of apixaban. Group 2 is divided into two arms: 9 months to 2 years given $2.43 \mathrm{mg} / \mathrm{m}^{2}$ of apixaban and 28 days to $<9$ months given $1.08 \mathrm{mg} / \mathrm{m}^{2}$ of the drug. Group 3 includes patients 2 years to $<6$ years old who are given a single-dose of apixaban at $1.17 \mathrm{mg} / \mathrm{m}^{2}$. Children ages 6 years to $<12$ years are assigned to Group 4 and are given apixaban $1.8 \mathrm{mg} / \mathrm{m}^{2}$, whereas adolescents in Group 5 are given $2.19 \mathrm{mg} / \mathrm{m}^{2}$ of apixaban. The primary outcomes of this study include the measurement of AUC, $C_{\max }$, and $T_{\max }$ of apixaban up to $26 \mathrm{~h}$ post drug administration. As secondary outcomes, the researchers monitor adverse events up to $26 \mathrm{~h}$ and 30 days post dose and evaluate the pharmacodynamic effect of apixaban by measuring anti-factor Xa level up to $26 \mathrm{~h}$ post dose [41].

The second study was recently presented as a poster at the previously mentioned XXV Congress of the International Society on Thrombosis and Haemostasis and 61st Annual Scientific and Standardization Committee Meeting [42, 43]. This is a phase III, multicenter, international, open-label, study that randomizes pediatric patients (ages 1 to $<18$ years) with acute lymphoblastic leukemia or lymphoma treated with L-asparaginase to either the placebo group or the intervention group. Patients who are 2 years old and above weighing less than $35 \mathrm{~kg}$ are given $0.05 \mathrm{mg} / \mathrm{kg}$ twice daily of apixaban as a $0.4 \mathrm{mg} / \mathrm{ml}$ solution and patients weighing $\geq 35 \mathrm{~kg}$ are given a $2.5-\mathrm{mg}$ tablet twice daily. Per the researchers, dosage for 12-23 months has yet to be determined. The primary endpoint of this study is a composite of non-fatal DVT/PE, cerebral venous sinus thrombosis, and VTE-related death up to 
1 month after therapy. The researchers are planning to recruit a total of 700 subjects. If this recruitment is successful, this will be the first adequately powered phase III clinical trial evaluating DOAC in the pediatric population $[42,43]$.

The last ongoing study will be a randomized, phase IV, open-label study evaluating the use of apixaban as a treatment option for acute venous thromboembolism in pediatric patients less than 18 years of age [44]. Subjects will be given either the standard of care (e.g., heparin or enoxaparin) or apixaban. Children 12 to $<18$ years old weighing less than $40 \mathrm{~kg}$ will receive an apixaban dose of $0.2 \mathrm{mg} / \mathrm{kg}$ twice daily for 7 days followed by $0.1 \mathrm{mg} / \mathrm{kg}$ twice daily, whereas children at the same age weighing more than $40 \mathrm{~kg}$ will receive the adult VTE treatment dose (i.e., $10 \mathrm{mg}$ twice daily for 7 days followed by $5 \mathrm{mg}$ twice daily). Dosages for patients less than 12 years old have not been mentioned. The primary outcomes of this study consist of the composite of major and non-major bleeding and the composite of confirmed symptomatic and asymptomatic recurrent VTE and mortality related to the VTE up to 12 weeks post treatment. Apixaban and anti-Xa levels will also be obtained as secondary endpoints. This study is estimated to be completed in October 2020 [44] (Fig. 2).

\section{Edoxaban}

Edoxaban is the most recently approved [January 2015 in the United States (US) and June 2015 in Europe] factor Xa inhibitor. Even though edoxaban does not have a novel mechanism of action, it exhibits some pharmacodynamic/pharmacokinetic advantages in anticoagulation. It has the fastest time to maximum effect (1-2 h) and offers options for once-daily dosing and for patients with renal impairment [45]. Also, its absorption is not affected by the presence of food [45]. Edoxaban is currently approved for the prevention of VTE in patients undergoing orthopedic surgery of the lower extremities, DVT/PE treatment 5-10 days after a parenteral anticoagulant has been used, as well as for stroke and systemic embolism risk reduction in NVAF. In the adult population, $60 \mathrm{mg}$ once daily is used for DVT/ PE treatment, with a dose reduction to $30 \mathrm{mg}$ once daily if the patient's creatinine clearance is between 15 and $50 \mathrm{ml} / \mathrm{min}$, on a concomitant P-glycoprotein (Pg-P) inhibitor, or weight is $\leq 60 \mathrm{~kg}$ [16]. The ENGAGE AF-TIMI 48 trial [46], which was a randomized, double-blind, non-inferiority study of high- and low-dose edoxaban (60 and $30 \mathrm{mg}$, respectively) compared to warfarin, showed that edoxaban was non-inferior to warfarin in preventing the primary end point of systemic embolism or stroke. In addition, edoxaban had a lower bleeding rate and death from cardiovascular causes in comparison to warfarin [46].

\section{Ongoing Study}

The only current pediatric study involving edoxaban is a phase I, open-label, preliminary pharmacodynamic and pharmacokinetic trial in patients 0-18 years old [47]. The dose matched to low and high adult doses (30 and $60 \mathrm{mg}$, respectively) will be given to children requiring oral anticoagulation as a single dose. There are currently eight arms in this study divided by age and low/high dose of edoxaban. The primary outcome is clearance between days 1 and 3 post dose, and the secondary outcomes include pharmacodynamic parameters that are measured with PT, aPTT, and anti-Xa levels, safety and tolerability, and metabolite exposure. This trial is currently recruiting patients and is expected to be completed in 2016 [47]. 


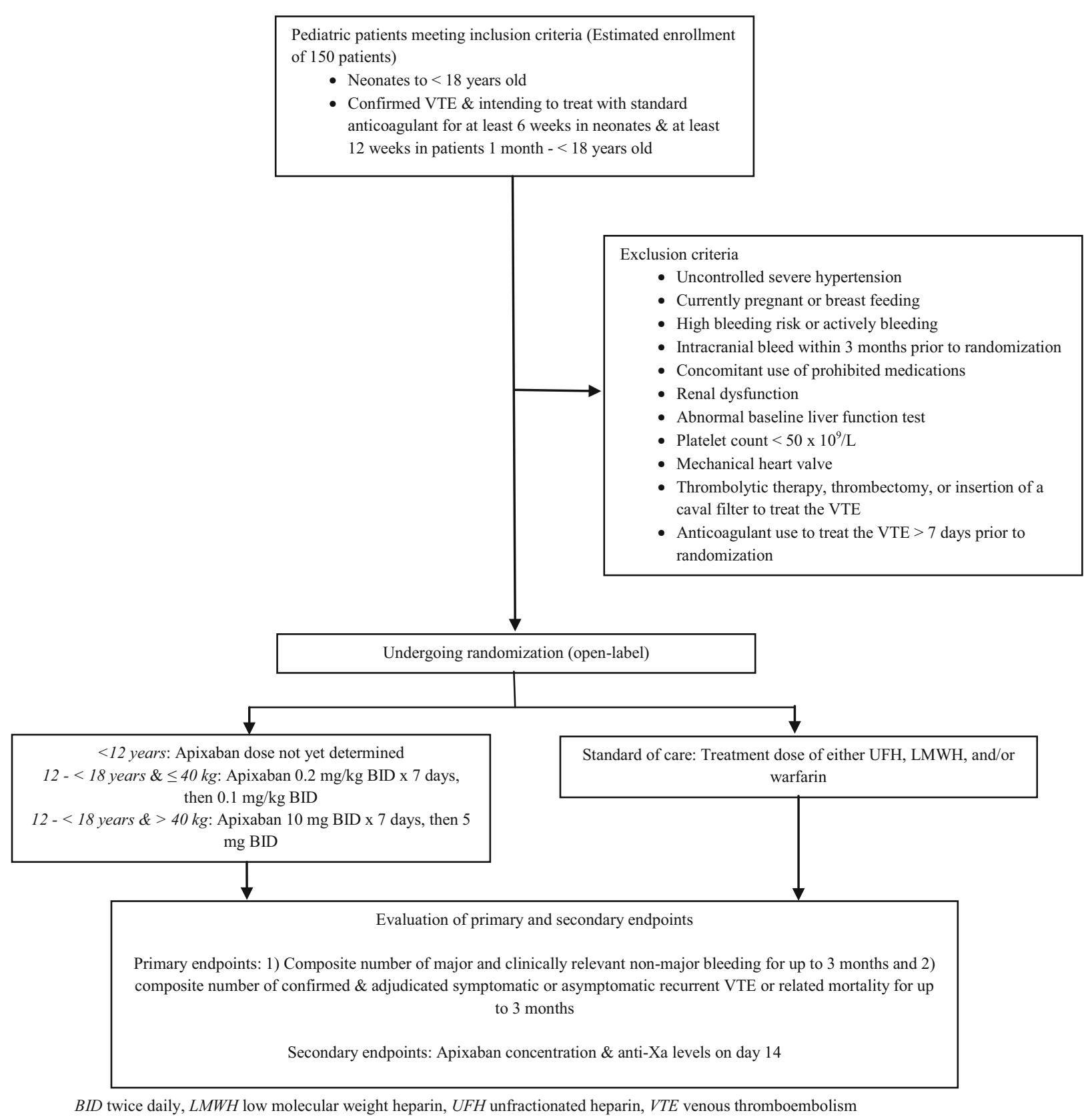

Fig. 2 Design of apixaban for the acute treatment of venous thromboembolism in children (Phase IV Study) [44]

Of note, from the ENGAGE AF-TIMI 48 study and the observation that about $50 \%$ of the dose of edoxaban is cleared by the kidneys [46], there is a direct correlation between serum drug levels and outcomes expected from edoxaban (i.e., decrease in the risk of stroke). The ENGAGE study proved this when it showed that patients with NVAF with $\mathrm{CrCL}>95 \mathrm{ml} / \mathrm{min}$ had a statistically higher rate of ischemic stroke with edoxaban in comparison to patients receiving warfarin. This observation resulted in a black box warning in the US for edoxaban 
recommending healthcare providers not to use this oral anticoagulant in patients with NVAF whose $\mathrm{CrCL}$ is $>95 \mathrm{ml} / \mathrm{min}$ [46]. However, this is listed only as a precaution, not a restriction, in the European drug label for edoxaban [17]. Even though this US warning is only in patients with NVAF and atrial fibrillation is an irrelevant diagnosis in pediatric patients, it will still be interesting to assess if edoxaban will be efficacious as an anticoagulant in this population, especially those $\geq 2$ years old, since they very well can have a $\mathrm{CrCL}>95 \mathrm{ml} / \mathrm{min} /$ $1.73 \mathrm{~m}^{2}$ [48]. With that being said, it is, however, not clear how the concentration of edoxaban may relate in these two different populations with different methods to assess renal function so clinicians should be cautions when trying to extrapolate this finding to children based on normalized body surface area.

\section{DIRECT THROMBIN INHIBITOR}

Thrombin converts fibrinogen to fibrin in the final step of the coagulation cascade. Inhibiting this step of the coagulation cascade inhibits free and bound thrombin, ultimately resulting in anticoagulation [18]. Dabigatran is currently the only oral medication in this class of anticoagulant.

\section{Dabigatran}

In the adult population, dabigatran is approved to treat DVT/PE as well as to reduce the risk of stroke/systemic embolism in NVAF. Approved doses for these indications are $150 \mathrm{mg}$ twice a day for CrCL $>30 \mathrm{ml} / \mathrm{min}$, with a dose adjustment to $75 \mathrm{mg}$ twice a day for CrCL $15-30 \mathrm{ml} / \mathrm{min}$ (i.e., for stroke reduction in NVAF only). Dabigatran is transported via the Pg-p efflux protein, and reaches $C_{\max }$ in about
$1 \mathrm{~h}$ if taken on an empty stomach. If given with a high-fat meal, the $C_{\max }$ increases to $2 \mathrm{~h}$, but there is not any change in the bioavailability of the medication [18]. In the RE-LY trial, 100 and $150 \mathrm{mg}$ of dabigatran were compared to warfarin in patients with NVAF. In this study, dabigatran was noninferior to warfarin for stroke and systemic embolism reduction [18]. Being a direct thrombin inhibitor, dabigatran binds to thrombin directly and is not dependent on the availability of antithrombin which can be very variable among patients, specifically pediatric patients [49]. In addition, there is also not any drug monitoring required with dabigatran, making it also a favorable option to explore in pediatric patients.

\section{Completed Studies}

A study was recently published assessing the effect of dabigatran in vitro using plasma samples and an assay with increasing concentrations of dabigatran [1]. The five clotting assays in this study included thrombin time (TT), dilute thrombin time (dTT), ecarin clotting time (ECT), aPTT, and PT. When evaluating response to increasing dabigatran concentrations $(0,50,250$, and $450 \mathrm{ng} / \mathrm{ml})$, there was not any difference among the different age groups of children ( 0 to $<1,1$ to $<5,5$ to $<10$, and 10 to $<17$ years). However, longer clotting times with respect to aPTT, ECT, and TT were observed in children compared to adults with increasing concentrations of dabigatran. Of all the assays, the dTT, TT, and ECT were most linearly correlated with increasing plasma concentrations, and the study concluded that dTT was the best assay for measuring dabigatran concentration in pediatric patients. The author concluded that this assay may be necessary to measure dabigatran concentrations until there 
are more studies looking into the pharmacodynamic and pharmacokinetic effects of this anticoagulant in the pediatric population [1].

Another open-label, phase II study was also completed in February 2012 in Canada in which the investigators aimed to evaluate the safety and tolerability of dabigatran given for 3 days to adolescents who had finished a course of standard anticoagulation for the primary diagnosis of VTE [50]. Nine subjects (mean age, $15.7 \pm 1.3$ years; six of them were female) were initially enrolled in this study. One of these subjects did not finish the study due to withdrawal, but he or she was included in the final analysis. All patients were given an initial dose of $1.71 \mathrm{mg} / \mathrm{kg}$ [75 mg (three patients); $100 \mathrm{mg}$ (three patients); $125 \mathrm{mg}$ (three patients)], which was $80 \%$ of the adult $150-\mathrm{mg}$ dose adjusted for a weight of $70 \mathrm{~kg}$. Thrombin time was then obtained and the dabigatran was adjusted to a target dose of $2.14 \mathrm{mg} / \mathrm{kg}$ twice daily (BID) [100 mg BID (three patients); $125 \mathrm{mg}$ BID (three patients); $150 \mathrm{mg}$ BID (two patients)]. None of these subjects had a major or minor bleeding event, but two of them experienced drug-related adverse events while on treatment and one subject reported a serious adverse event $72 \mathrm{~h}$ post-treatment (exact descriptions of these events were not documented). Free and total dabigatran concentrations were also obtained in six of the subjects. The subjects who received a final dosage of $100 \mathrm{mg}$ BID had a mean free and total dabigatran concentration of 28 and $34.2 \mathrm{ng} / \mathrm{ml}$, respectively; whereas the $125 \mathrm{mg}$ BID, 41.6 and $58.2 \mathrm{ng} / \mathrm{ml}$, respectively [50]. Even though this particular study had a small sample size, the results can potentially add to the body of literature and provide other investigators a plausible initial dosage of dabigatran for adolescents involved in larger future studies.

\section{Ongoing Studies}

Currently, there are three phase II trials being conducted on the use of an oral dabigatran liquid formulation in the pediatric population [51-53]. Two of these studies aim to evaluate the pharmacokinetic/pharmacodynamic data, safety, and tolerability of this solution in children who are at the end of their standard anticoagulation course for a VTE diagnosis [51, 52]. The first study is enrolling infants less than 1 year of age (excluding $<3 \mathrm{~kg}$ ) [51], whereas the other study is evaluating the use of this solution in children 1 to 2 years old (excluding $<9 \mathrm{~kg}$ ) [52]. Patients will be given an age- and weight-adjusted equivalent dose of dabigatran. The exact doses being used in these studies, however, are not currently available. Some common primary endpoints between these two studies include the measurement of total plasma concentrations of dabigatran, ECT, and aPTT. The study with infants $<1$ year of age is also looking at anti-factor IIa activity 2 and $12 \mathrm{~h}$ post dose [51], whereas the other study is also evaluating the incidence of bleeding and adverse events as additional primary endpoints [52]. The global assessment of tolerability of the liquid medication is also being assessed as one of the secondary endpoints $[51,52]$. The last of this phase II trial [53] has similar primary and secondary endpoints to the one being conducted in children 1 to 2 years old [52], but the former is an international study and the investigators are evaluating the use of this oral dabigatran solution in children 1 to 12 years old [53]. The results of all these three previously mentioned studies are vital to establishing a bio-equivalent oral suspension of dabigatran in the pediatric population. 
On the other hand, there are currently two phase III trials evaluating the safety and efficacy of dabigatran in pediatric patients $[54,55]$. The first study is an open-label, non-inferiority study comparing dabigatran with standard of care (i.e., warfarin, UFH, or LMWH) to treat patients with VTE. It has a co-primary endpoint of thrombus resolution with freedom from recurrent VTE in addition to freedom from major bleeding events. The VTE must have been diagnosed and already been treated with UFH or LMWH for 5-7 days with an indication to treat with anticoagulants for at least 3 months post diagnosis [54] (Fig. 3). In another open-label study, dabigatran is being evaluated as a secondary prophylaxis for VTE in children ages $0-18$ years [55]. The endpoints for this study include VTE recurrence, bleeding events (major and minor), and mortality associated with thrombotic events. These patients must have finished their previous course of anticoagulants for the initial VTE to be eligible for this study [55]. The results of all of these ongoing studies are pending and yet to be published. Table 1 summarizes the information on the completed trials and those being performed on the use of DOACs in the pediatric population.

\section{CLINICAL APPLICATION}

Current anticoagulants recommended for the use in pediatric patients with VTE include UFH, LMWH, and warfarin [2]. There are several limitations to the use of these agents that make the DOACs desirable. Disadvantages to the use of unfractionated heparin include the need for continuous intravenous access and frequent therapeutic drug level monitoring. Although LMWH does not require intravenous access, it requires twice-daily subcutaneous administration, which may not be ideal for pediatric patients who are often afraid of needles/injections. Also, anti-Xa levels are often required to be monitored in pediatric patients on LMWH [2]. Finally, warfarin, although it has the advantage of being a once-daily oral anticoagulant, it requires frequent international normalized ratio (INR) monitoring and carries multiple drug and food interactions that may require frequent dose adjustments [56].

The DOACs, including rivaroxaban, apixaban, dabigatran, and most recently edoxaban, offer the possibility of improved dose stability, oral routes of administration, infrequent drug monitoring, and fewer drug and food interactions [56]. A disadvantage to the use of these agents in comparison to the standard therapies is the lack of an established reversal agent for pediatric patients in the case of a major bleeding event or accidental/ intentional overdose [57]. Fortunately, it seems that accidental or intentional one-time, low-dose ingestion of rivaroxaban and dabigatran does not lead to clinically significant bleeding as demonstrated by cases called into the California Poison Control system from January 2011 to July 2013 [58]. Nonetheless, an effective reversal agent for pediatric patients is indicated. Idarucizumab was recently approved in the US in October 2015 for the reversal of dabigatran in adults [59-61]. Currently, two additional reversal agents are in development: andexanet alfa and ciraparantag. Both of these agents can potentially reverse the oral factor Xa inhibitors as a class, and the latter may also reverse the effect of dabigatran [62]. Even though efficacy data on these reversal agents do not currently exist in pediatric patients, it will be really important for these agents to be evaluated in this population in the near future. 


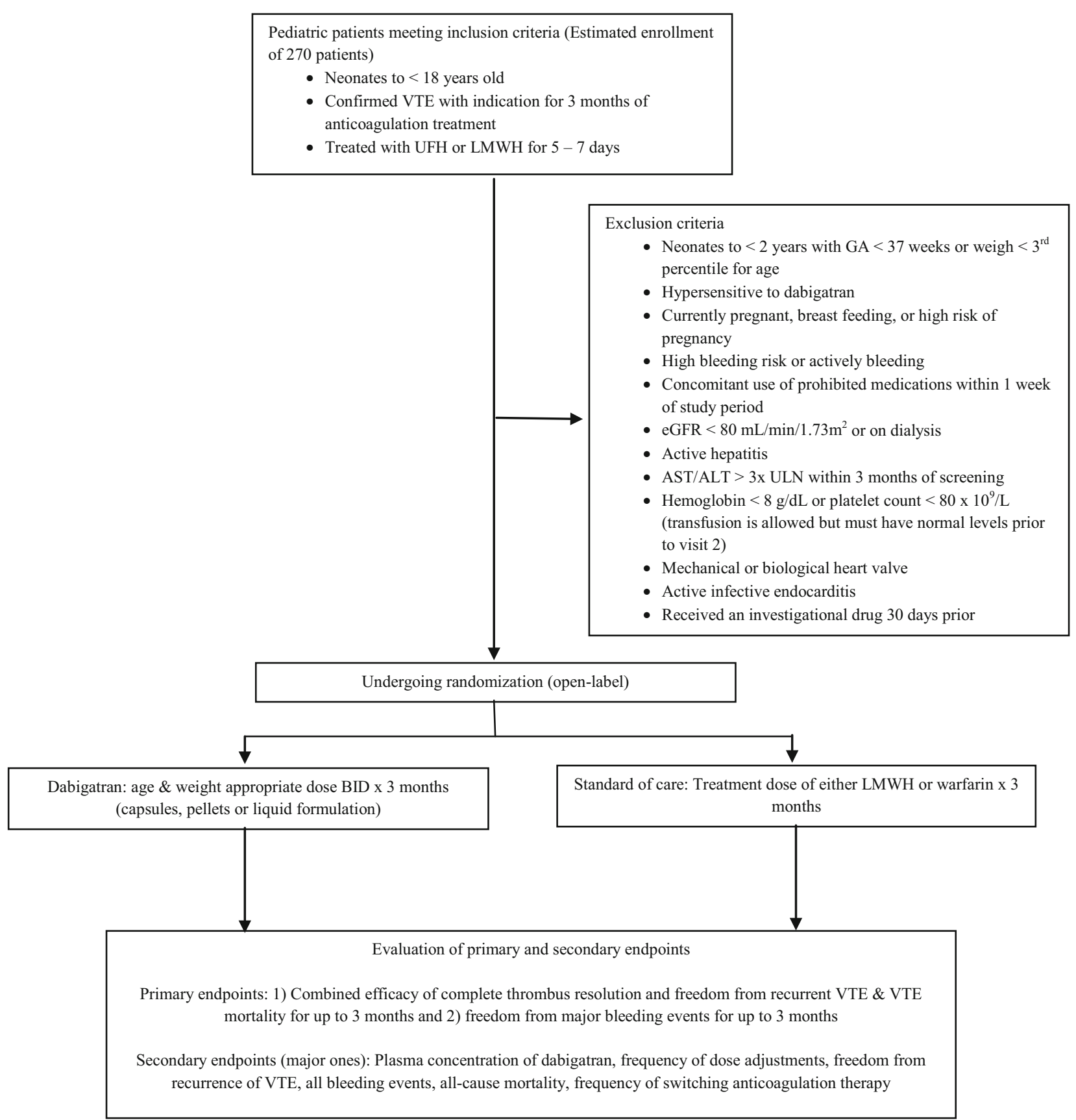

BID twice daily, eGFR estimated glomerular filtration rate, GA gestational age, $L M W H$ low molecular weight heparin, $U F H$ unfractionated heparin, $U L N$ upper limit of normal, VTE venous thromboembolism

Fig. 3 Design of the efficacy and safety comparison of dabigatran etexilate to standard of care in pediatric patients with venous thromboembolism (Phase III Study) [54]

Based on the current literature, treatment of VTE in the pediatric population should always be initiated with UFH, LMWH, or warfarin. It is still too early to recommend one of the DOACs as an initial alternative for such indication due to the lack of published clinical trials. More data 


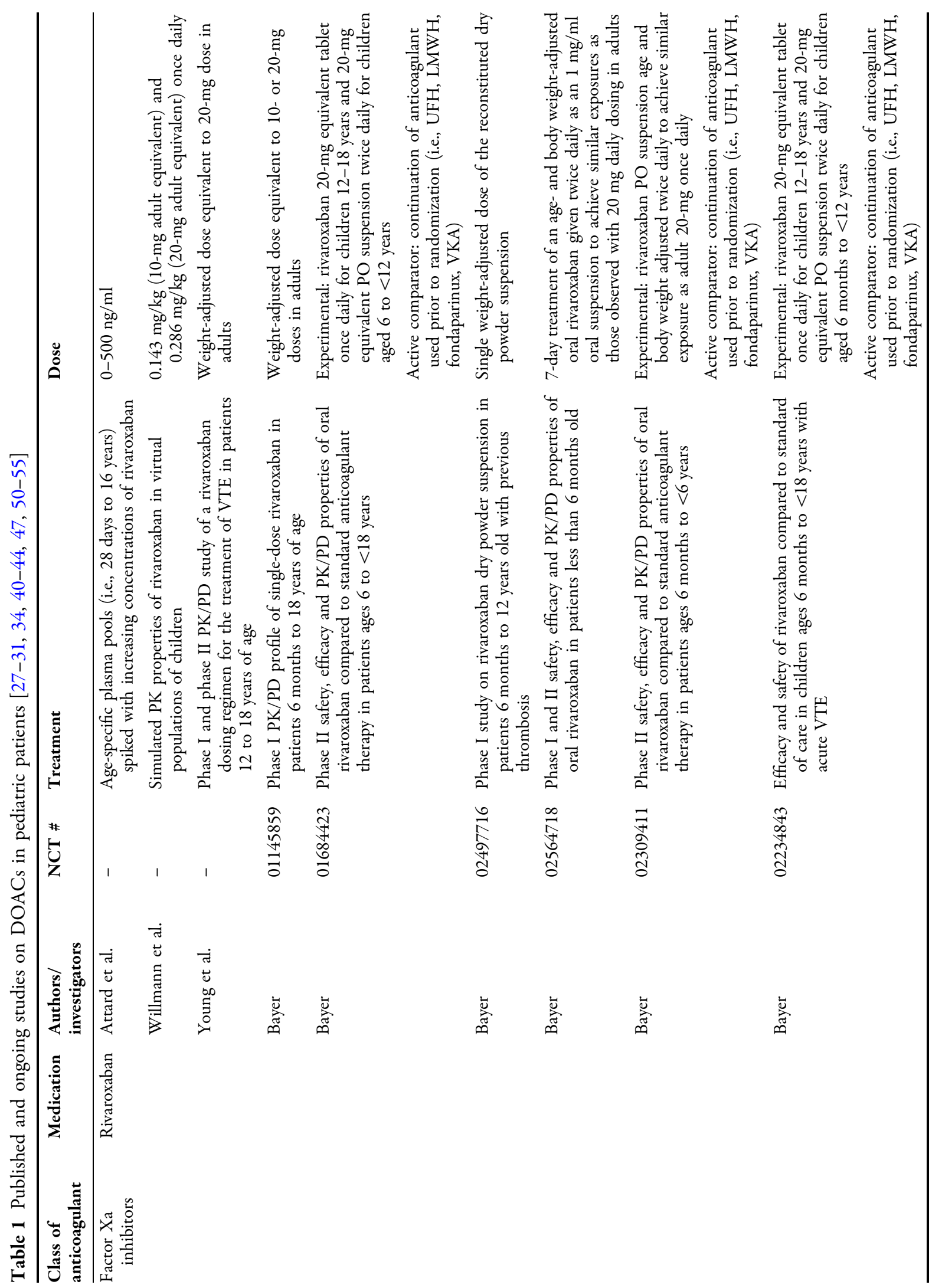




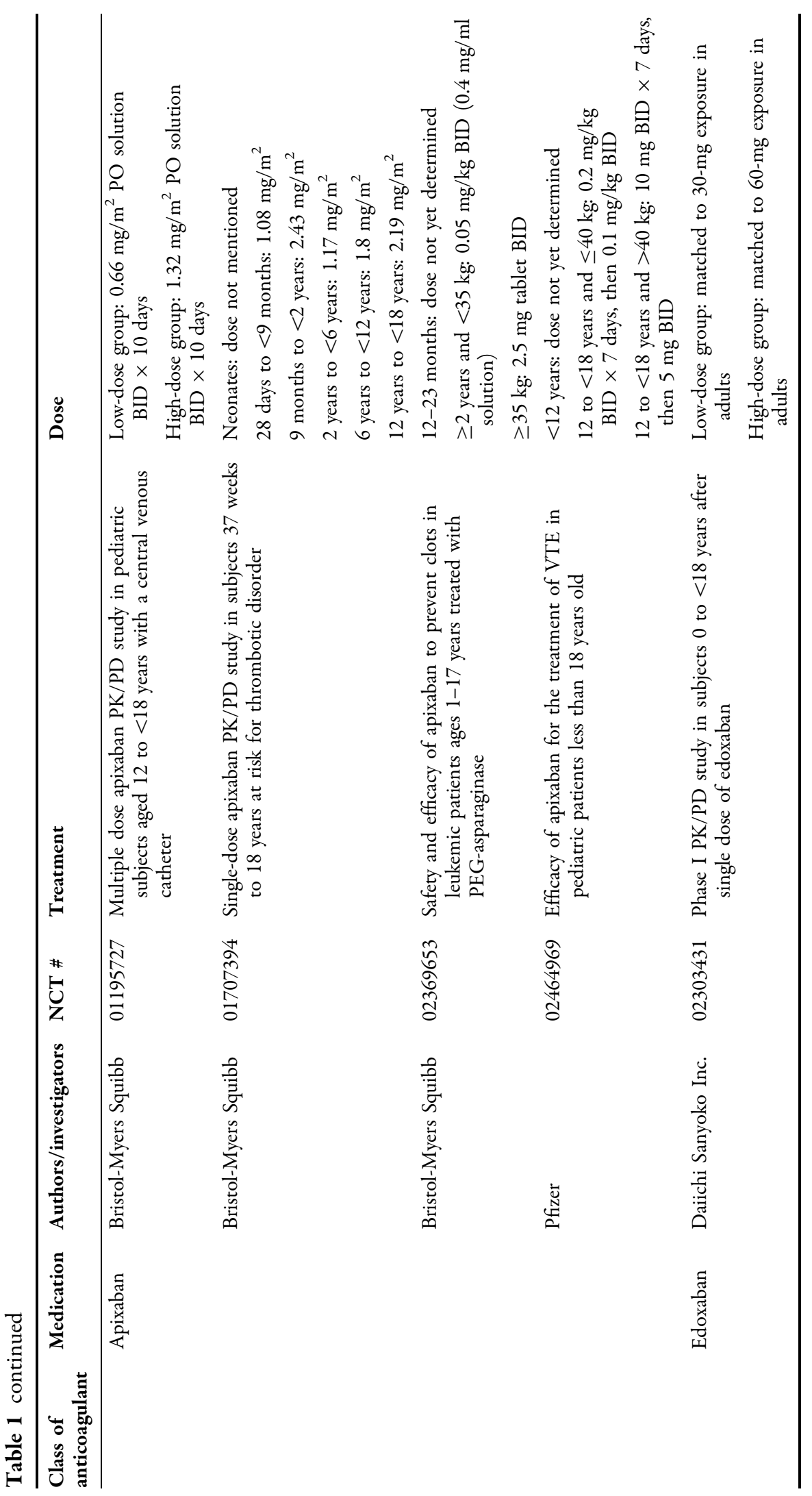




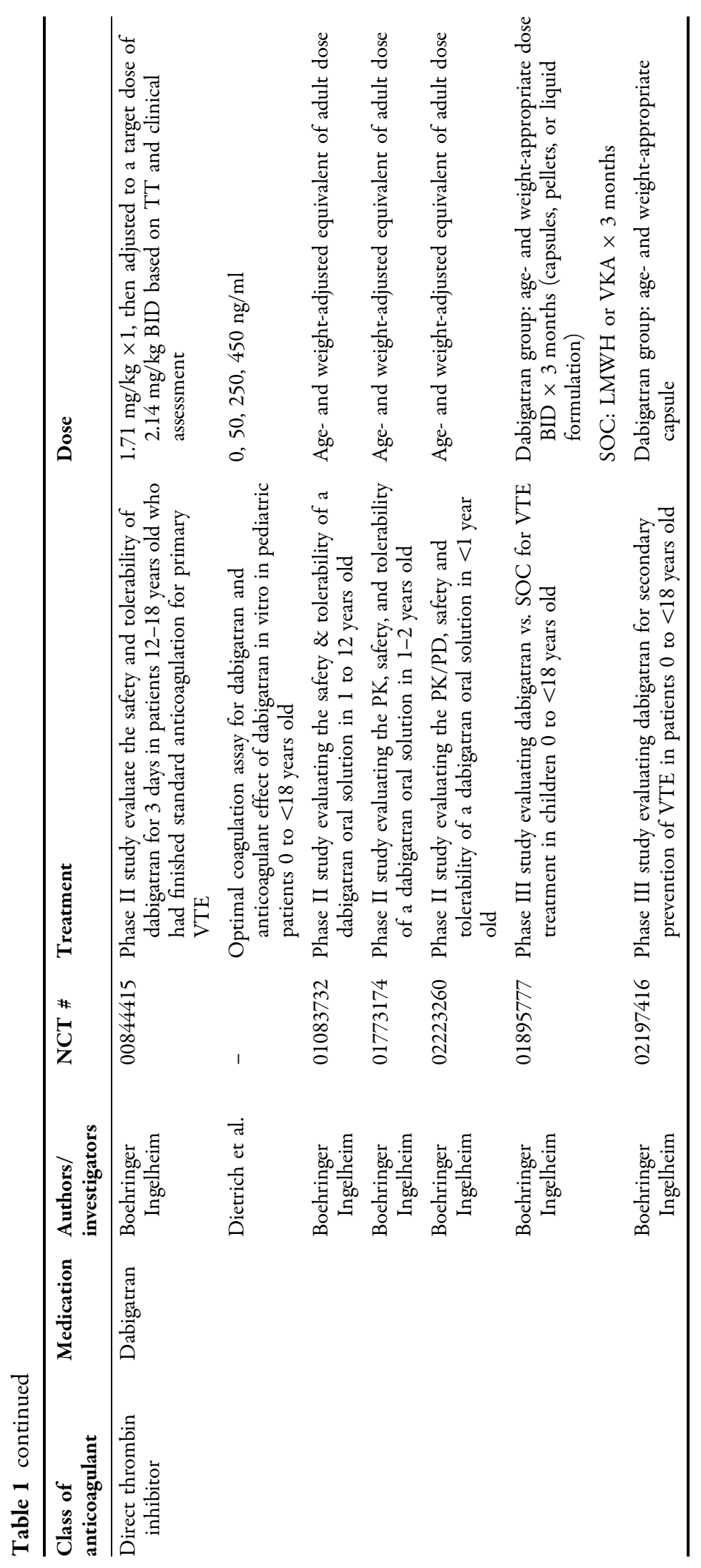




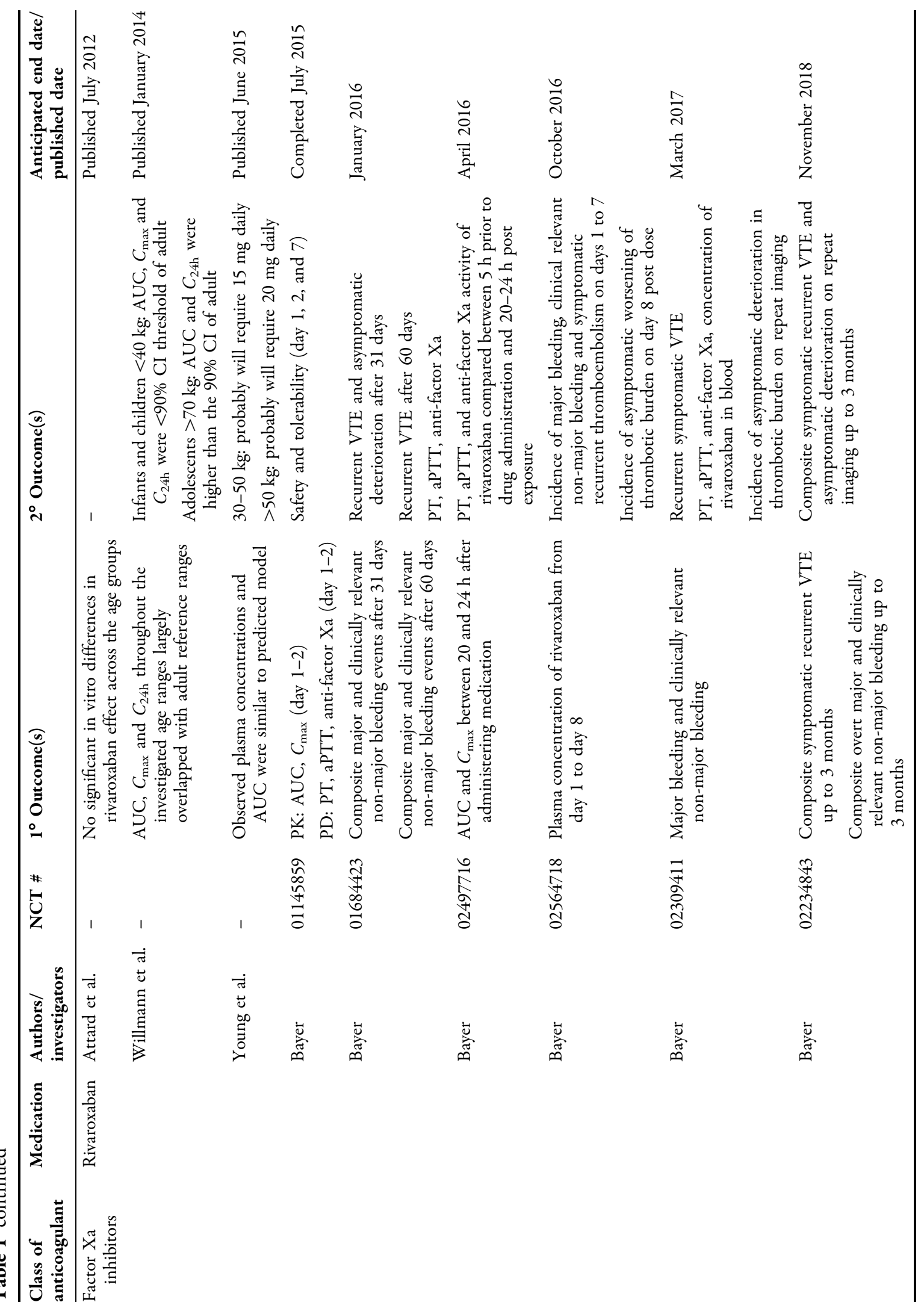




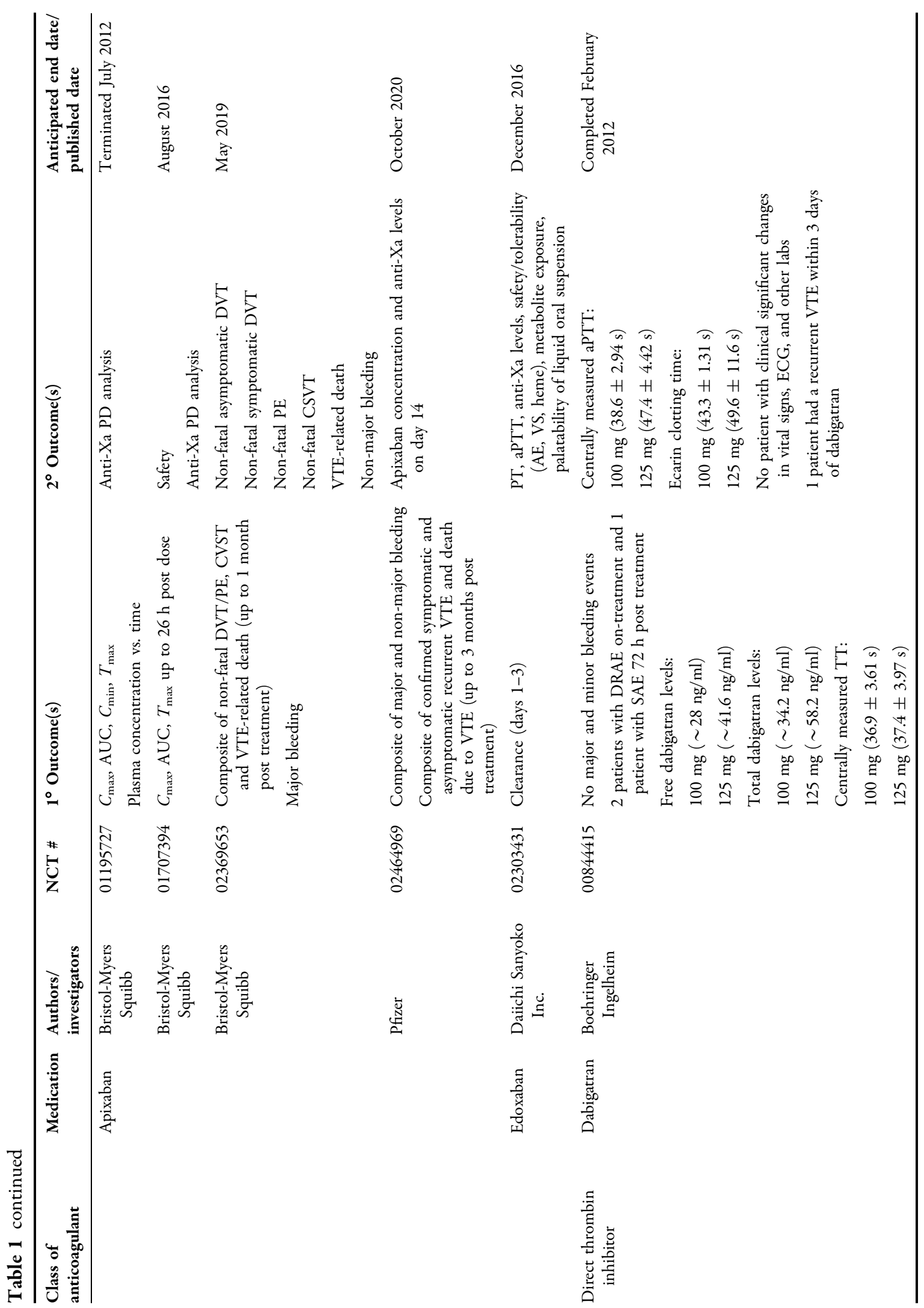




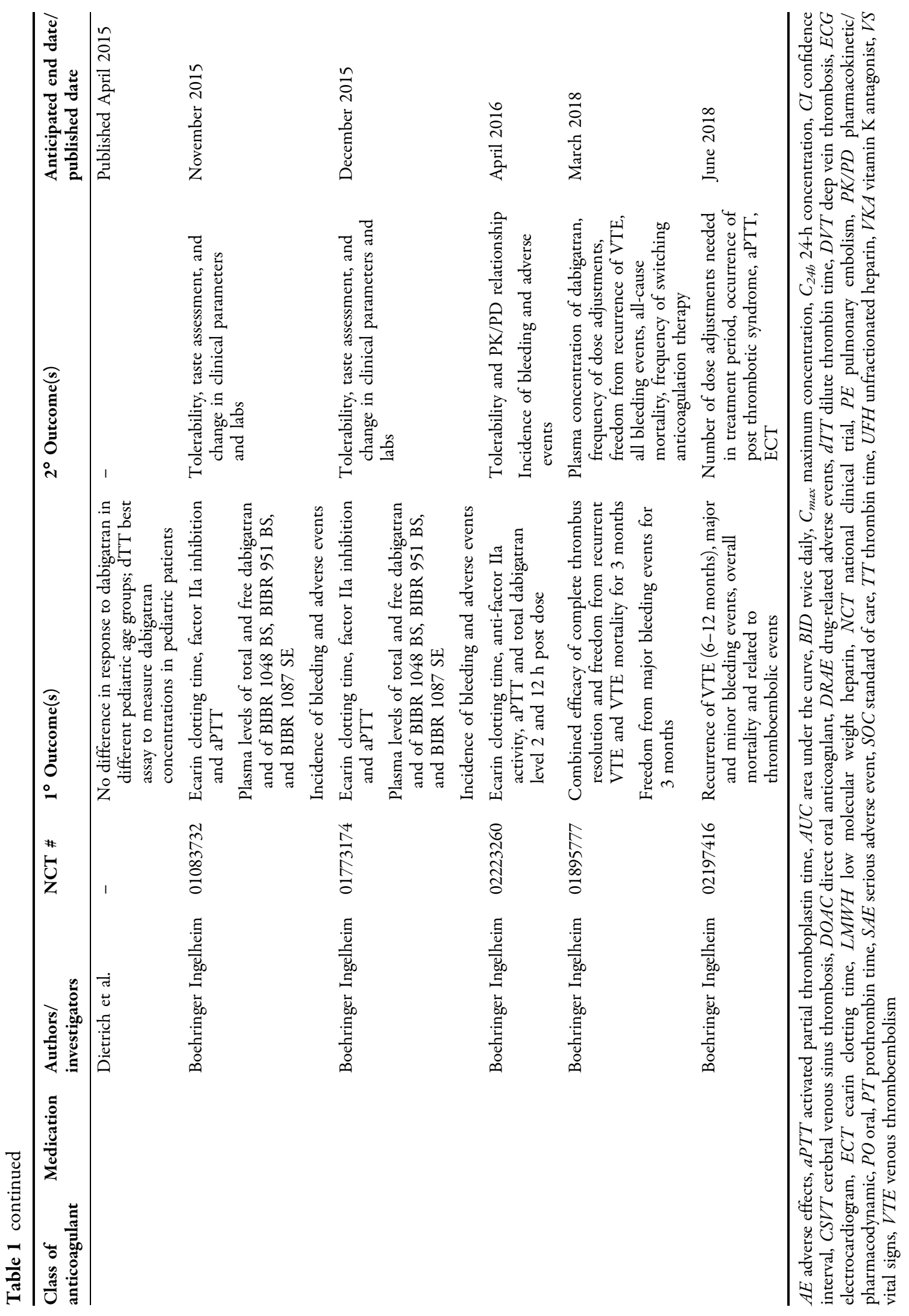


are needed to determine the appropriate dosing of these agents in different age groups. For example, the evidence available for the use of rivaroxaban in this population only includes the outcomes of four completed studies assessing its pharmacokinetic and pharmacodynamic effects in a simulated model as well as an in vitro analysis. The outcomes of these trials suggested that there are minimal age-related differences in pharmacokinetic and pharmacodynamic effects of rivaroxaban except in children less than $40 \mathrm{~kg}$ of body weight $[19,25]$. In this specific population, serum concentrations were found to be significantly reduced, suggesting the need for higher doses. These data also presented that children more than $70 \mathrm{~kg}$ had significantly different AUC and $C_{24 \mathrm{~h}}$, and therefore, using adult-based dosing of rivaroxaban can lead to very different pharmacokinetic and pharmacodynamic results in these children [19]. On the other hand, pharmacokinetic and pharmacodynamic results of apixaban and edoxaban should surely drive their use in children since the available data suggested different dosing in patients less than $60 \mathrm{~kg}$, as would be the case in most pediatric patients. In summary, clinicians should wait for more clinical studies to be completed before recommending the use of DOAC in this special population.

\section{CONCLUSIONS}

Pediatric thromboembolic complications requiring the use of anticoagulation continues to be a concern for this patient population especially in regard to its associated morbidity and mortality. Due to the lack of clinical evidence on the use of DOACs in this population, their use should not be considered as first-line therapy. Instead, UFH, LMWH, or warfarin should first be initiated. Since many studies related to DOACs are ongoing, clinicians should wait for them to be completed before making any definitive recommendations on using these agents in children. When the results of the multiple ongoing phase III studies are completed and published, a revised pediatric anticoagulation guideline will surely be warranted.

\section{ACKNOWLEDGMENTS}

No funding or sponsorship was received for this study or publication of this article. All named authors meet the International Committee of Medical Journal Editors (ICMJE) criteria for authorship for this manuscript, take responsibility for the integrity of the work as a whole, and have given final approval for the version to be published.

Disclosures. Erika von Vajna, Ruhaniyah Alam, and Tsz-Yin So have nothing to declare.

Compliance with ethical guidelines. This article is based on previously conducted studies and does not involve any new studies of human or animal subjects performed by any of the authors.

Open Access. This article is distributed under the terms of the Creative Commons Attribution-NonCommercial 4.0 International License (http://creativecommons.org/licenses/ by-nc/4.0/), which permits any noncommercial use, distribution, and reproduction in any medium, provided you give appropriate credit to the original author(s) and the source, provide a link to the Creative Commons license, and indicate if changes were made. 


\section{REFERENCES}

1. Dietrich K, Stang L, Van Ryn J, Mitchell LG. Assessing the anticoagulant effect of dabigatran in children: an in vitro study. Thromb Res. 2015;135(4):630-5.

2. Monagle $\mathrm{P}$, Chan AK, Goldenberg NA, et al. Antithrombotic therapy in neonates and children: antithrombotic therapy and prevention of thrombosis, 9th ed: American College of Chest Physicians Evidence-Based Clinical Practice Guidelines. Chest. 2012;141(2 Suppl):e737S-801S.

3. Cetta F, Graham LC, Wrona LL, Arruda MJ, Walenga JM. Argatroban use during pediatric interventional cardiac catheterization. Catheter Cardiovasc Interv. 2004;61:147-9.

4. Kawada T, Kitagawa H, Hoson M, Okada Y, Shiomura J. Clinical application of argatroban as an alternative anticoagulant for extracorporeal circulation. Hematol Oncol Clin N Am. 2000;14:445-57.

5. Severin T, Zieger B, Sutor AH. Anticoagulation with recombinant hirudin and danaparoid sodium in pediatric patients. Semin Thromb Hemost. 2002;28:447-54.

6. Young G, Nugent DJ. Use of argatroban and fondaparinux in a child with heparin-induced thrombocytopenia. Pediatr Blood Cancer. 2004;42(suppl):542 (abstract).

7. Boshkov LK, Kirby A, Shen I, et al. Recognition and management of heparin-induced thrombocytopenia in pediatric cardiopulmonary bypass patients. Ann Thorac Surg. 2006;81:S2355-9.

8. Grabowski EF, Bussell JB. Pediatric experience with fondaparinux in deep vein thrombosis. Blood. 2006;108:916 (abstract).

9. Sharatkumar AA, Crandall C, Lin JJ, et al. Treatment of thrombosis with fondaparinux (Arixtra) in a patient with end-stage renal disease receiving hemodialysis therapy. J Pediatr Hematol Oncol. 2007;29:581-4.

10. Young G, Yee DL, O'Brien S, Khanna R, Nugent DJ. FondaKIDS: a prospective dose finding, pharmacokinetic, and safety study of fondaparinux in children between 1-18 years of age. Pediatr Blood Cancer. 2011;57(6):1049-54.

11. Deitcher SR, Topoulos AP, Bartholomew JR, Kichuk-Chrisant MR. Lepirudin anticoagulation for heparin-induced thrombocytopenia. J Pediatr. 2002;140:264-6.
12. Shantsila E, Lip GYH, Chong BH. Heparin-induced thrombocytopenia: a contemporary clinical approach to diagnosis and management. Chest. 2009;135:1651-4.

13. Yeh $\mathrm{CH}$, Fredenburgh JC, Weitz JI. Oral direct factor Xa inhibitors. Circ Res. 2012;111(8):1069-78.

14. Xarelto (rivaroxaban) [prescribing information]. Gurabo, PR: Janssen Pharmaceuticals Inc; September 2014.

15. Eliquis (apixaban) [prescribing information]. Princeton, NJ: Bristol-Myers Squibb; March 2014.

16. Savaysa (edoxaban) [prescribing information]. Parsippany, NJ: Daiichi Sankyo; January 2015.

17. Lixiana (edoxaban) [prescribing information]. Munich, Germany: Daiichi Sankyo; June 2015.

18. Pradaxa (dabigatran) [prescribing information]. Ridgefield, CT: Boehringer Ingelheim Pharmaceuticals, Inc; August 2014.

19. Willmann S, Becker C, Burghaus $\mathrm{R}$, et al. Development of a paediatric population-based model of the pharmacokinetics of rivaroxaban. Clin Pharmacokinet. 2014;53(1):89-102.

20. Lassen MR, Ageno W, Borris LC, et al. Rivaroxaban versus enoxaparin for thromboprophylaxis after total knee arthroplasty. $\mathrm{N}$ Engl J Med. 2008;358(26):2776-86.

21. Eriksson BI, Borris LC, Friedman RJ, et al. Rivaroxaban versus enoxaparin for thromboprophylaxis after hip arthroplasty. N Engl J Med. 2008;358(26):2765-75.

22. EINSTEIN Investigators, Bauersachs $\mathrm{R}$, Berkowitz $\mathrm{SD}$, Brenner $\mathrm{B}$, et al. Oral rivaroxaban for symptomatic venous thromboembolism. N Engl J Med. 2010;363(26):2499-510.

23. Patel MR, Mahaffey KW, Garg J, et al. Rivaroxaban versus warfarin in nonvalvular atrial fibrillation. N Engl J Med. 2011;365(10):883-91.

24. EINSTEIN-PE Investigators. Oral rivaroxaban for the treatment of symptomatic pulmonary embolism. New Engl J Med. 2012;366(14):1287-97.

25. Attard C, et al. The in vitro anticoagulant effect of rivaroxaban in children. Thromb Res. 2012;130(5):804-7.

26. Young G, Kubitza D, Chan A, et al. Development of a rivaroxaban dosing regimen for treatment of VTE in children aged 12 to 18 years. J Throm Haemost. 2015;13(Suppl 2):37. 
27. Bayer. Rivaroxaban pharmacokinetics/ pharmacodynamics (PK/PD) study in pediatric subjects. In: ClinicalTrials.gov [Internet]. Bethesda (MD): National Library of Medicine (US). 2000. NLM Identifier: NCT01145859. https://clinicaltrials. gov/ct2/show/NCT01145859. Accessed 15 Jun 2015.

28. Bayer. EINSTEIN Junior Phase II: Oral rivaroxaban in young children with venous thrombosis (EINSTEINJr). In: ClinicalTrials.gov [Internet]. Bethesda (MD): National Library of Medicine (US). 2000. NLM Identifier: NCT02309411. https:// clinicaltrials.gov/ct2/show/NCT02309411. Accessed 15 Jun 2015.

29. Bayer. Oral rivaroxaban in children with venous thrombosis (EINSTEINJunior). In: ClinicalTrials.gov [Internet]. Bethesda (MD): National Library of Medicine (US). 2000. NLM Identifier: 01684423. https:/clinicaltrials.gov/ct2/show/NCT01684423. Accessed 15 Jun 2015.

30. Bayer. EINSTEIN Junior Phase III: oral rivaroxaban in children with venous thrombosis (EINSTEIN Jr). In: ClinicalTrials.gov [Internet]. Bethesda (MD): National Library of Medicine (US). 2000. NLM Identifier: NCT02234843. https://clinicaltrials.gov/ ct2/show/NCT02234843. Accessed 15 Jun 2015.

31. Bayer. Phase I study on rivaroxaban dry powder suspension in children. In: ClinicalTrials.gov [Internet]. Bethesda (MD): National Library of Medicine (US). 2000. NLM Identifier: NCT02497716. https:/clinicaltrials.gov/ct2/show/ NCT02497716. Accessed 07 Oct 2015.

32. Bayer. Relative bioavailability of oral suspension of rivaroxaban compared to standard table. In: ClinicalTrials.gov [Internet]. Bethesda (MD): National Library of Medicine (US). 2000. NLM Identifier: NCT01853800. https://clinicaltrials.gov/ ct2/show/NCT01853800. Accessed 07 Oct 2015.

33. Bayer. Relative bioavailability study in healthy subjects comparing 2 dry powder oral suspensions of rivaroxaban under fasting and $20 \mathrm{mg}$ of an oral suspension of rivaroxaban under fed conditions to $10 \mathrm{mg}$ of an immediate release tablet under fasting conditions. In: ClinicalTrials.gov [Internet]. Bethesda (MD): National Library of Medicine (US). 2000. NLM Identifier: NCT02367027. https:// clinicaltrials.gov/ct2/show/NCT02367027. Accessed 07 Oct 2015.

34. Bayer. Rivaroxaban for treatment in venous or arterial catheter related thrombosis in neonates. In: ClinicalTrials.gov [Internet]. Bethesda (MD): National Library of Medicine (US). 2000. NLM Identifier: NCT02564718. https://clinicaltrials.gov/ ct2/show/NCT02564718. Accessed 13 Nov 2015.
35. Lassen MR, Gallus A, Raskob GE, et al. Apixaban versus enoxaparin for thromboprophylaxis after hip replacement. N Engl J Med. 2010;363(26):2487-98.

36. Lassen MR, Raskob GE, Gallus A, et al. Apixaban versus enoxaparin for thromboprophylaxis after knee replacement (ADVANCE-2): a randomised double-blind trial. Lancet. 2010;375(9717):807-15.

37. Granger $\mathrm{CB}$, Alexander $\mathrm{JH}$, McMurray JJ, et al. Apixaban versus warfarin in patients with atrial fibrillation. N Engl J Med. 2011;365(11):981-92.

38. Agnelli G, Buller HR, Cohen A, et al. Apixaban for extended treatment of venous thromboembolism. N Engl J Med. 2013;368(8):699-708.

39. Agnelli G, Buller HR, Cohen A, et al. Oral apixaban for the treatment of acute venous thromboembolism. N Engl J Med. 2013;369(9):799-808.

40. Bristol-Myers Squibb. Multiple-dose study apixaban in pediatric subjects with an indwelling central venous catheter. In: ClinicalTrials.gov [internet]. Bethesda (MD): National Library of Medicine (US). 2000. NLM identifier: NCT01195727. https:// clinicaltrials.gov/ct2/show/NCT01195727. Accessed 15 Jun 2015

41. Bristol-Myers Squibb. Study to evaluate a single dose of apixaban in pediatric subjects at risk for a thrombotic disorder. In: ClinicalTrials.gov [Internet]. Bethesda (MD): National Library of Medicine (US). 2000. NLM Identifier: NCT01707394. https://clinicaltrials.gov/ct2/show/ NCT01707394. Accessed 07 Oct 2015.

42. Rodriguez V, O'Brien S, Sung L, et al. Rationale and design of AESOP: apixaban for prevention of deep vein thrombosis in pediatric patients with acute lympho blastic leukemia or lymphoma treated with L-asparaginase. J Throm Haemost. 2015;13(Suppl 2):425.

43. Bristol-Myers Squibb. Safety and efficacy study of apixaban to prevent clots in children with leukemia who have a central venous catheter and are treated with Peg Asparaginase. In: ClinicalTrials.gov [Internet]. Bethesda (MD): National Library of Medicine (US). 2000. NLM Identifier: NCT02369653. https://clinicaltrials.gov/ct2/show/ NCT02369653. Accessed 07 Oct 2015.

44. Pfizer. Apixaban for the acute treatment of venous thromboembolism in children. In: ClinicalTrials.gov [Internet]. Bethesda (MD): National Library of Medicine (US). 2000 [cited 2015 Oct 07]. NLM Identifier: NCT02464969. https://clinicaltrials.gov/ct2/show/NCT02464969. Accessed 07 Oct 2015. 
45. Schulman S. Advantages and limitations of the new anticoagulants. J Intern Med. 2014;275(1):1-11.

46. Giugliano RP, Ruff CT, Braunwald E, et al. Edoxaban versus warfarin in patients with atrial fibrillation. N Engl J Med. 2013;369(22):2093-104.

47. Daiichi Sanyko. A Phase 1, open-label, single-dose, non-randomized study to evaluate pharmacokinetics and pharmacodynamics of edoxaban in pediatric patients. In: ClinicalTrials.gov [internet]. Bethesda (MD): National Library of Medicine (US). 2000. NLM identifier: NCT02303431. https://clinicaltrials.gov/ ct2/show/NCT02303431. Accessed 15 Jun 2015.

48. Chan JC, Williams DM, Roth KS. Kidney failure in infants and children. Pediatr Rev. 2002;23(2):47-60.

49. Dabbous MK, Sakr FR, Malaeb DN. Anticoagulant therapy in pediatrics. J Basic Clin Pharm. 2014;5(2):27-33.

50. Boehringer Ingelheim. Safety and tolerability of dabigatran etexilate in adolescents. In: ClinicalTrials.gov [Internet]. Bethesda (MD): National Library of Medicine (US). 2000. NLM Identifier: NCT00844415. https://clinicaltrials.gov/ ct2/show/NCT00844415. Accessed 15 Oct 2015.

51. Boehringer Ingelheim. Tolerability, PK/PD and safety of dabigatran etexilate oral liquid formulation in children $<1$ year of age. In: ClinicalTrials.gov [internet]. Bethesda (MD): National Library of Medicine (US). 2000. NLM identifier: NCT02223260. https://clinicaltrials.gov/ ct2/show/NCT02223260. Accessed 15 Oct 2015.

52. Boehringer Ingelheim. Pharmacokinetics, safety and tolerability of dabigatran etexilate solution in children 1 to $<2$ years of age. In: ClinicalTrials.gov [internet]. Bethesda (MD): National Library of Medicine (US). 2000. NLM identifier: NCT01773174. https:/clinicaltrials.gov/ct2/show/ NCT01773174. Accessed 15 Oct 2015.

53. Boehringer Ingelheim. Safety and tolerability of dabigatran etexilate solution in children 1 to $<12$ years of age. In: ClinicalTrials.gov [internet]. Bethesda (MD): National Library of Medicine (US). 2000. NLM identifier: NCT01083732. https:// clinicaltrials.gov/ct2/show/NCT01083732. Accessed 15 Oct 2015.
54. Boehringer Ingelheim. Open label study comparing efficacy and safety of dabigatran etexilate to standard of care in paediatric patients with venous thromboembolism (VTE). In: ClinicalTrials.gov [internet]. Bethesda (MD): National Library of Medicine (US). 2000 [cited 2015 Jun 15]. NLM identifier: NCT01895777. https://clinicaltrials.gov/ ct2/show/record/NCT01895777. Accessed 15 Jun 2015.

55. Boehringer Ingelheim. Safety of dabigatran etexilate in blood clot prevention in children. In: ClinicalTrials.gov [internet]. Bethesda (MD): National Library of Medicine (US). 2000. NLM identifier: NCT02197416. https://clinicaltrials.gov/ ct2/show/NCT02197416. Accessed 15 Jun 2015.

56. Kerlin BA. Current and future management of pediatric venous thromboembolism. Am J Hematol. 2012;87(1 Suppl):S68-74.

57. Wadhera RK, et al. Warfarin versus novel oral anticoagulants: how to choose? Circulation. 2014;130(22):e191-3.

58. Stevenson JW, Minns AB, Smollin C, et al. An observation case series of dabigatran and rivaroxaban exposures reported to a poison control system. Am J Emerg Med. 2014;32:1077-84.

59. Pollack CV, Reilly PA, Bernstein R, et al. Design and rational for RE-VERSE AD: a phase 3 study of idarucizumab, a specific reversal agent for dabigatran. Throm Haemost. 2015;114:198-205.

60. Pollack CV, Reilly PA, Eikelboom J, et al. Idarucizumab for dabigatran reversal. $\mathrm{N}$ Engl J Med. 2015;373:511-20.

61. Glund S, Stangier J, Schmohl M, et al. Safety, tolerability, and efficacy of idarucizumab for the reversal of the anticoagulant effect of dabigatran in healthy male volunteers: a randomized, placebo-controlled, double-blind phase 1 trial. Lancet. 2015;386:680-90.

62. Ansell JE. Universal, class-specific and drug-specific reversal agents for the new oral anticoagulants. J Thromb Thrombolysis 2015; Oct 8 (Epub ahead of print). 